\title{
PANEL: Viewing Engineering Education through the Lens of Social Science: A Candid Dialogue on Race and Gender
}

\section{Dr. William H. Robinson III, Vanderbilt University}

William H. Robinson received his B.S. in electrical engineering from the Florida Agricultural and Mechanical University (FAMU) in 1996 and his M.S. in electrical engineering from the Georgia Institute of Technology (Georgia Tech) in 1998. He received his Ph.D. in electrical and computer engineering from Georgia Tech in 2003. In August 2003, Dr. Robinson joined the Department of Electrical Engineering and Computer Science (EECS) at Vanderbilt University as an Assistant Professor, and was promoted to Associate Professor in 2010. He is the first African American to earn promotion and win tenure in the Vanderbilt University School of Engineering. Currently, he serves as Associate Chair of the EECS Department. He also serves as the Director of Undergraduate Studies for both electrical engineering and computer engineering. Dr. Robinson leads the Security And Fault Tolerance (SAF-T) Research Group at Vanderbilt University, whose mission is to conduct transformational research that addresses the reliability and security of computing systems.

Dr. Robinson's major honors include selection for a National Science Foundation (NSF) Faculty Early Career Development (CAREER) Program Award and the Defense Advanced Research Projects Agency (DARPA) Computer Science Study Panel, both in 2008. He received two awards from FAMU, a Young Alumni Award in 2010 and an Outstanding Alumni of the Quasquicentennial Award in 2012. Dr. Robinson is a Senior Member of both the Institute of Electrical and Electronics Engineers (IEEE) and the Association for Computing Machinery (ACM); he has membership in the American Society for Engineering Education (ASEE), and is a Lifetime Member of the National Society of Black Engineers (NSBE). Dr. Robinson is a Life Member of Alpha Phi Alpha Fraternity, Inc. and a member of The 100 Black Men of Middle Tennessee, Inc.

\section{Dr. Ebony O. McGee, Vanderbilt University}

Ebony O. McGee is an Assistant Professor of Diversity and Urban Schooling at Vanderbilt University's Peabody College and a member of Scientific Careers Research and Development Group at Northwestern University. She received her Ph.D. in Mathematics Education from the University of Illinois at Chicago; and she was a National Academy of Education/Spencer Foundation Postdoctoral Fellow and a National Science Foundation Postdoctoral Fellow. As a former electrical engineer, she is concerned with science, technology, engineering, and mathematics (STEM) learning and participation among historically marginalized students of color. Her research focuses on the role of racialized experiences and biases in STEM educational and career attainment, problematizing traditional notions of academic achievement and what is mean to be successful yet marginalized, and STEM identity and identity development in high-achieving students of color. She is currently the PI on two studies funded by NSF, the first of which investigates the causes behind why African Americans remain one of the most underrepresented racial groups in engineering faculty positions. The second study is working toward the design of a holistic racial and gender attentive mentoring program for engineering $\mathrm{PhD}$ students of color. 
ASEE Workshop: 2016 New Orleans

\section{PANEL: Viewing Engineering Education through the Lens of Social Science: A Candid Dialogue on Race and Gender}

Engineering faculty members and industry professionals play a crucial and multi-faceted role in science and engineering; they help to discover, promote, and disseminate advancements in technology, as well as educate a future workforce of multi-cultural, multiracial engineers. It follows that a thorough understanding of racial and gender disparities is required: (1) to address the complexity of issues facing potential faculty and professionals and (2) to foster greater numbers of Black engineers into academia and industry.

There has been a concerted national effort to promote diversity among the engineering research, industry, and faculty communities for more than 40 years. These programs historically focus on the basic mechanisms of an academic or industry career (e.g., the tenure-track process, grant writing, writing a winning CV). However, the efficacy of programs aimed at producing Black engineering faculty and professionals must be examined given the flat percentage of Black engineering faculty near $2.5 \%$ for the past decade. To that end, we seek to investigate the degree to which intersectionality (i.e., the interplay of racial stereotypes, gender biases, and other issues) within the engineering education has been addressed for diversity.

We argue that engineering education does not adequately addresses race, gender, and other types of bias that require the input of multiple perspectives. Scholarly contributions from fields such as sociology, psychology, and education, in addition to engineering perspectives, will facilitate a greater positive impact for Black Ph.D. and postdoctoral participants. Thus, this panel will be informed by understandings about: (1) the social construction of race, (2) the impact of discrimination on mental health and wellness, and (3) education as a means of transformational change. The work of contributing scholars from fields outside of science and engineering focuses on several crucial areas, including: (1) race, culture, and social stratification; (2) social justice in education; (3) mathematical and racial identity; (4) racial socialization processes; and, (5) race and gender intersectionalities. From this range of expertise, the panel will be able to integrate relevant strands into the challenge of diversity that faces engineering education.

This proposed panel seeks to provide the increased awareness of engineering as a profession impacted by racialized and gendered factors that create particular difficulties for Black engineering students who pursue academia or industry. Many of these students are coping with societal constraints. Consequently, this panel will provide assistance in creating effective strategies to transcend traditional boundaries that typically impede their opportunity to pursue engineering employment, in particular, when they are also faced with the need to address a host of negative racial and gendered experiences. The panelists were asked to review the findings presented by McGee et al. [1] in order to provides research perspectives, resources, and insightful narrative videos on strategies for navigating and supporting the experiences of Black engineering graduate students and faculty. 
The panel discussion would address key questions, including: How does structural racism manifest in the everyday experiences of students and teachers of color in higher education? Do these experiences manifest differently in engineering contexts? What is the role of mentorship in fostering a healthy and culturally affirming identity in students and professionals of color in engineering? What can institutions do to create or improve their climate so that it enhances the opportunities of their students of color in engineering and recognizes and fosters the brilliance of these students?

\section{Scheduled Panelists and their Research Interests:}

- Dr. Dorinda J. Carter Andrews, Associate Professor, Department of Teacher Education, Michigan State University

Dr. Carter Andrews' long-term interests as a teacher, scholar, and citizen focus on race and equity in education. She studies black student identity and achievement in suburban and urban contexts, urban teacher preparation, and critical race praxis with K-12 educators. In her professional roles at Michigan State University, she participate in and contribute to a range of scholarly conversations about and projects related to these topics. Her professional activities and accomplishments address these topics and mutually inform one another across her scholarship, teaching, and service.

- Dr. Robbin Chapman, Associate Provost and Academic Director of Diversity and Inclusion; and Lecturer, Department of Education, Wellesley College

Associate Provost Chapman has been at Wellesley College since 2011 where she provides strategic leadership and vision for the College's diversity, academic, and faculty initiatives. As a member of The Partnerships for Diversity \& Inclusion team, Dr. Chapman partners with her colleagues, Robin Cook-Nobles, director of the counseling service and interim director of the Office of Intercultural Education, and Carolyn Slaboden, assistant vice president and director of human resources and equal opportunity, to promote and support equity efforts across the campus. Professor Chapman works with the Pforzheimer Learning and Teaching Center on faculty development and student achievement issues and with academic departments as they conduct searches for new faculty members. In addition, she leads special projects on behalf of the provost's office.

- Dr. Jomo Mutegi, Associate Professor of Science Education, School of Education, Indiana University-Purdue University Indianapolis

Dr. Mutegi's research agenda, which addresses the underrepresentation of African Americans in science and science-related careers, consists of three lines of scholarship. In the first, he explores students' science knowledge as a factor that influences career decisions. In the second line of scholarship, he explores racism in student teacher interactions to determine the degree to which race bias inhibits African Americans from pursuing science and science-related careers. The third and most central line of scholarship is educational praxis. Herein he works to use science education as a tool for improving the African American community. 
- Dr. David Stovall, Associate Professor of African American Studies and Educational Policy Studies, University of Illinois at Chicago

David Omotoso Stovall is a professor of Educational Policy Studies and African-American Studies. His research interests include critical race theory, school-community relationships, youth culture, and the relationship between housing and K-12 school systems. Stovall studies the influence of race in urban education, community development, and housing. His work investigates the significance of race in the quality of schools located in communities that are changing both racially and economically. From a practical and theoretical perspective, his research draws from Critical Race Theory, educational policy analysis, sociology, urban planning, political science, community organizing, and youth culture.

\section{Facilitators:}

- Dr. Ebony O. McGee, Assistant Professor of Diversity and STEM Education, Department of Teaching and Learning, Vanderbilt University

- Dr. William H. Robinson, Associate Dean, School of Engineering, and Associate Professor of Electrical Engineering, Vanderbilt University

McGee and Robinson have collaborated on a study to examine the factors that impact the production of African American Ph.D.'s in engineering, as well as those factors that affect the pathway to tenured faculty positions in engineering. Their findings have highlighted the need to discuss race and gender and its impact on developing a more diverse engineering workforce [1-4].

\section{References}

[1] E. O. McGee, W. H. Robinson, L. C. Bentley, and S. L. Houston II, "Diversity stalled: Explorations into the stagnant numbers of African American engineering faculty," in ASEE Annual Conference and Exposition, Seattle, WA, 2015.

[2] W. H. Robinson, E. O. McGee, L. C. Bentley, S. L. Houston II, P. K. Botchway, and R. Roy, "Racial and gendered experiences that dissuade a career in the professoriate," in Research on Equity and Sustained Participation in Engineering, Computing, and Technology (RESPECT), Charlotte, NC, 2015, pp. 1-5.

[3] W. H. Robinson, E. O. McGee, L. C. Bentley, S. L. Houston, and P. K. Botchway, "Addressing negative racial and gendered experiences that discourage academic careers in engineering," Computing in Science \& Engineering, vol. 18, pp. 29-39, 2016.

[4] E. O. McGee, L. Bentley, S. Houston, D. Smith, W. H. Robinson, and P. K. Botchway, "The motivation behind PhD attainment for Black engineering doctoral students: Passion plus purpose," Journal for Multicultural Education, (in press). 